Pesq. Vet. Bras. 30(3):211-218, março 2010

\title{
Sensibilidade da técnica de imuno-histoquímica em fragmentos de sistema nervoso central de bovinos e equinos naturalmente infectados pelo vírus da raiva ${ }^{1}$
}

\author{
Samira M. Achkar², Elaine R. Fernandes ${ }^{3}$, Maria Luiza Carrieri², Andréa B.M. \\ de Castro $^{2}$, Alexandre M. Batista ${ }^{2}$, Maria Irma S. Duarte ${ }^{3}$ e Ivanete Kotait ${ }^{2}$
}

\begin{abstract}
Achkar S.M., Fernandes E.R., Carrieri M.L., Castro A.B.M., Batista A.M., Duarte M.I.S. \& Kotait I. 2010. [Sensitivity of the Immunohistochemistry technique in central nervous system fragments of cattle and horses naturally infected by rabies virus.] Sensibilidade da técnica de imuno-histoquímica em fragmentos de sistema nervoso central de bovinos e equinos naturalmente infectados pelo vírus da raiva. Pesquisa Veterinária Brasileira 30(3):211-218. Instituto Pasteur, Av. Paulista 393, Cerqueira César, São Paulo, SP 01311-000, Brazil. E-mail: samira_achkar@yahoo.com.br

Rabies is a viral zoonosis that causes disease in the central nervous system (CNS) of mammals and it is considered a serious problem of public health. Herbivorous (bovines and equines) are often infected after being attacked by vampire bats (Desmodus rotundus). The direct fluorescent antibody technique is used as a diagnostic test to detect viral antigens in fresh tissues and is recommended by the World Health Organization. The immunohistochemistry technique $(\mathrm{IHC})$ is used to detect the viral antigen through the use of monoclonal/policlonal antibodies in formalin-fixed tissues. The aim of this work was to evaluate the sensitivity of the IHC in samples of CNS of herbivorous fixed in formol, analyzing the antigenic distribution in different fragments of the CNS. The results demonstrated good agreement between the two techniques for the rabies diagnosis. The IHC presented higher sensitivity in samples of cattle comparing to horse samples, especially in fragments of cerebellum and brain stem. These fragments demonstrated to be more suitable for antigen detection by both techniques in the two species. These data demonstrate that the IHC is suitable for rabies vigilance yet cautions should be taken in examining cattle and horses samples, when the submitted specimen is only the hippocampus.
\end{abstract}

INDEX TERMS: Rabies, immunohistochemistry, direct fluorescent antibody test, sensitivity, herbivorous.

RESUMO.- A raiva é uma zoonose viral que acomete o sistema nervoso central (SNC) de mamíferos, considerada um grave problema de saúde pública. Herbívoros (bovinos e equinos) são frequentemente acometidos pela infecção após serem atacados por morcegos hematófagos (Desmodus rotundus). A técnica de imunofluorescência direta (IFD) realizada em tecidos frescos, recomendada

\footnotetext{
${ }^{1}$ Recebido em 30 de junho de 2009.

Aceito para publicação em 1 de outubro de 2009.

2 Instituto Pasteur, Avenida Paulista 393, Bairro Cerqueira César, São Paulo, SP 01311-000, Brasil. *Autor para correspondência: samira_achkar@yahoo.com.br

${ }^{3}$ Laboratório da Disciplina de Patologia de Moléstias Transmissíveis, Faculdade de Medicina, Universidade de São Paulo. Av. Dr. Arnaldo 455, Cerqueira César, São Paulo, SP 01246-903, Brasil.
}

pela Organização Mundial de Saúde (OMS), é utilizada para o diagnóstico da raiva. A técnica de imuno-histoquímica (IHQ) é utilizada para detectar antígenos em tecidos fixados, pelo uso de anticorpos monoclonais/policlonais. O objetivo deste trabalho foi avaliar a sensibilidade da $\mathrm{IHQ}$ na detecção de antígenos do vírus da raiva em amostras de SNC de herbívoros fixadas em formol, analisando a distribuição antigênica em diferentes fragmentos do SNC. Os resultados demonstraram concordância das técnicas de IFD e IHQ. A IHQ mostrou maior sensibilidade em amostras de bovinos em relação às de equinos, especialmente quando realizada em fragmentos de cerebelo $e$ tronco encefálico. A detecção de antígeno nestes fragmentos foi mais consistente para ambas as técnicas, nas duas espécies. Estes resultados demonstram que a IHQ 
pode ser empregada para a vigilância epidemiológica da raiva, entretanto, recomenda-se cautela ao se empregar a IHQ para diagnóstico de doença em herbívoros, especialmente quando o fragmento encaminhado ao laboratório for apenas o hipocampo.

TERMOS DE INDEXAÇÃO: Raiva, imuno-histoquímica, imunofluorescência direta, sensibilidade, herbívoros.

\section{INTRODUÇÃO}

A raiva é considerada uma das zoonoses de maior importância em saúde pública, não só por sua evolução letal, mas também por seu custo social e econômico. A enfermidade é caracterizada por uma encefalite aguda fatal e é mantida e perpetuada na natureza por várias espécies animais, denominadas reservatórios, que podem ser carnívoros domésticos e silvestres ou morcegos de diferentes hábitos alimentares (Smith 1996).

A doença é causada pelo vírus da raiva, pertencente ao gênero Lyssavirus, família Rhabdoviridae, ordem Mononegavirales (Fauquet et al. 2005). A instalação da infecção depende do contato do agente com soluções de continuidade da pele já existentes ou provocadas por mordeduras, que é a principal forma de transmissão, e/ou arranhaduras, ou com membranas mucosas (Brass 1994, Acha \& Szyfres 1996).

Atualmente no Brasil, a raiva humana, cuja incidência tem diminuído, vem sendo transmitida por cães e morcegos hematófagos, que se alternam em importância epidemiológica (Brasil 2009). O ciclo silvestre é mantido entre carnívoros silvestres e quirópteros. O ciclo rural é representado principalmente pelo morcego hematófago Desmodus rotundus, responsável pela transmissão do vírus para herbívoros, que são hospedeiros acidentais, pois, apesar de integrarem a cadeia epidemiológica, atuam apenas como sentinelas e hospedeiros terminais da doença. Assim, a probabilidade de transmissão destes a outros animais é baixa, por estes hospedeiros apresentarem principalmente a característica paralítica, diferentemente da sintomatologia furiosa, observada nos casos de raiva em carnívoros (Rupprecht et al. 2002).

A raiva em bovinos foi diagnosticada pela primeira vez por Carini em 1911, no Estado de Santa Catarina, em que foram identificados corpúsculos de Negri em cérebros de bovinos mortos por uma doença até então misteriosa (Carini 1911). Em 1916, veterinários alemães contratados pelo governo catarinense identificaram o Corpúsculo de Negri, que é a inclusão característica produzida pela infecção pelo vírus da raiva, em cérebros de morcegos hematófagos, confirmando a hipótese de Carini (Haupt \& Rehaag 1925).

Segundo dados da Organização Panamericana da Saúde (OPAS), a raiva em animais de interesse econômico ocorre principalmente nos países da América Latina, e está relacionada à presença do Desmodus rotundus. $\mathrm{O}$ ataque destes morcegos aos bovinos acarreta sérios prejuízos à pecuária, pois além dos animais mortos pela doença, os agredidos perdem peso e apresentam lesões em diversas partes do corpo, o que prejudica a qualidade do couro. Esta situação epidemiológica vem aumentando devido a fatores como a falta de uma política de combate mais efetiva e o desequilíbrio ecológico, esse último provocando a destruição de florestas e, consequentemente, migração destes morcegos para áreas com atividade rural, à procura de alimentos (Feital \& Confalonieri 1998).

Em herbívoros, a raiva pode apresentar variações no quadro clínico, e muitos dos sinais podem estar presentes em outras doenças que causam distúrbios neurológicos. Assim, o exame clínico não deve ser utilizado como único critério para o diagnóstico da enfermidade (Mori \& Lemos 1998).

Em bovinos, a forma paralítica é a mais frequente e o período de incubação pode variar de 30 a 90 dias (Kotait et al. 1998). A duração da doença é de 2 a 5 dias, podendo chegar a 10 dias (Acha \& Szyfres 1996).

O combate à raiva dos herbívoros é realizado por ações que devem ser realizadas em conjunto, como: controle de morcegos hematófagos, vacinação sistemática de herbívoros com mais de três meses de idade, e educação em saúde. Os animais primovacinados devem ser revacinados após trinta dias. Em áreas epizoóticas, a vacinação deve ser semestral (Kotait et al. 1998).

Não existe um teste diagnóstico conclusivo no animal vivo que confirme a suspeita clínica. No entanto, existem procedimentos laboratoriais padronizados internacionalmente para amostras obtidas post mortem de animais ou humanos suspeitos de raiva. As técnicas laboratoriais são aplicadas preferencialmente nos tecidos removidos do SNC. Fragmentos do hipocampo, tronco encefálico, tálamo, córtex, cerebelo e medula oblongata são tidos tradicionalmente como materiais de escolha (Tierkel 1976).

Os testes recomendados pela Organização Mundial de Saúde (OMS) e amplamente utilizados para o diagnóstico da raiva são a imunofluorescência direta (IFD) (Dean et al., 1996) e o isolamento viral (IV), que é realizado em sistemas sensíveis, como camundongos (IVC) (Koprowsky et al. 1996) e/ou em cultivo celular (ICC) (Webster \& Casey 1996).

Outras metodologias são utilizadas como ferramentas diagnósticas: a tipificação antigênica, utilizando um painel de anticorpos monoclonais para caracterizar variantes antigênicas (Diaz et al. 1994), a transcrição reversa seguida da reação em cadeia pela polimerase (RT-PCR) (Tordo et al. 1995) e o sequenciamento do DNA e análise filogenética (Carnieli Jr et al. 2009).

O fato de a vigilância epidemiológica não atingir todas as regiões geográficas, em função das dificuldades de manter as amostras sob refrigeração e/ou congelamento, torna necessária uma mudança nos procedimentos de preservação de amostras suspeitas de raiva a serem enviadas ao laboratório. Assim, a inviabilidade de procedimentos, como a conservação em gelo ou em glicerina (que compromete o diagnóstico pela IFD), pode ser substituída pela fixação do material em soluções alcoólicas ou 
aldeídicas, permitindo a submissão de testes diagnósticos, como a técnica de imuno-histoquímica (IHQ).

O objetivo do presente estudo foi avaliar a sensibilidade da técnica de Imuno-histoquímica no diagnóstico da raiva, em fragmentos de SNC de bovinos e equinos naturalmente infectados, considerando-se a IFD como técnica padrão.

\section{MATERIAL E MÉTODOS}

Amostras. Foram estudadas 20 amostras de SNC de herbívoros suspeitos de raiva, provenientes de diversas localidades do Estado de São Paulo, sendo 10 de equinos e 10 de bovinos.

Imunofluorescência direta (IFD). A partir das amostras de SNC, foram preparadas duas lâminas de cada fragmento: hipocampo $(\mathrm{H})$, córtex cerebral $(\mathrm{CX})$, cerebelo $(\mathrm{CB})$ e tronco encefálico (TE). As lâminas foram submetidas à IFD, de acordo com a técnica descrita por Dean et al. em 1996, pelo uso de conjugado anti-rábico policlonal antinucleocapsídeo, produzido no Instituto Pasteur de São Paulo, a partir de soro hiperimune de coelho.

Isolamento viral em camundongos (IVC). Como parte do protocolo recomendado pela OMS, foi feito o IVC. Foram preparadas duas suspensões a $20 \%$ (peso/volume) a partir de fragmentos de SNC suspeitos, sendo uma de pool de CX e CB e uma de TE. Cada suspensão foi inoculada por via intracerebral em sete camundongos albinos suíços de 21 dias, com peso entre 11 e $14 \mathrm{~g}$.

Imuno-histoquímica (IHQ). Para a técnica de IHQ, fragmentos frescos de $\mathrm{H}, \mathrm{CX}, \mathrm{CB}$ e TE, de aproximadamente $6 \mathrm{~mm}$, foram cortados e fixados em formol tamponado a $10 \%$ por 24 horas. Posteriormente, foram submetidos a lavagens sequenciais para desidratação, diafanização e inclusão em parafina. Por microtomia, cada fragmento foi submetido a cortes de $5 \mu$ em quatro lâminas, sendo três para a avaliação por IHQ e uma para contra-coloração por Hematoxilina-Eosina (HE).

Para a detecção do antígeno viral, foi utilizada a técnica de IHQ baseada na ligação do anticorpo primário ao antígeno encontrado no tecido. Foi utilizado como anticorpo primário, um soro policlonal anti-raiva, produzido no Instituto Evandro Chagas (PA). O método empregado foi estreptavidina-biotinaperoxidase (Bourgan \& Charlton 1987). Esta metodologia foi padronizada no Laboratório da Disciplina de Patologia de Moléstias Transmissíveis do Departamento de Patologia da Faculdade de Medicina da Universidade de São Paulo (Fernandes 2009).

Interpretação dos resultados. A interpretação foi realizada a partir da leitura das lâminas, sendo utilizado um microscópio de epifluorescência para a IFD e um microscópio óptico para a $I H Q$.

A determinação da positividade das técnicas foi feita pela leitura das lâminas, tendo a distribuição antigênica como parâmetro. A determinação das cinco classes que refletem a intensidade das reações foi realizada segundo critérios utilizados por Carrieri et al. (2006), sendo, classe 0 (-), a ausência de inclusões antigênicas; classe $1(+)$, com rara presença de antígenos, com apenas 1 a 3 pequenas inclusões; classe $2(++)$, quando há presença de campos negativos e escasso número de inclusões; classe $3(+++)$, quando há uma distribuição homogênea de antígenos, mesmo tendo campos negativos; e classe $4(++++)$, quando ocorrer distribuição homogênea de antígenos, porém sem campos negativos (Carrieri et al. 2006).

A avaliação da sensibilidade da técnica de $\mathrm{IHQ}$ em relação à IFD foi calculada a partir da relação entre a positividade nos diferentes fragmentos de SNC. Para tanto, foi utilizado o seguinte cálculo: $S_{{ }_{\mathrm{HQ}}}=\mathrm{P}_{\mathrm{IHQ}} / \mathrm{P}_{\mathrm{IFD}}$, sendo $\mathrm{S}_{\mathrm{IHQ}}=$ sensibilidade da técnica de IHQ, $P_{\mathrm{IHQ}}=$ positividade da técnica de $\mathrm{IHQ}$ e $\mathrm{P}_{\mathrm{IFD}}=$ positividade da técnica de IFD (Forattini 1980).

\section{RESULTADOS}

\section{Imunofluorescência direta (IFD)}

Todas as amostras analisadas foram positivas para a raiva pela IFD. A leitura das lâminas demonstrou maior distribuição de antígeno e, portanto, maior intensidade de fluorescência (+++ ou ++++) em fragmentos de CB e TE.

\section{Isolamento viral em camundongos (IVC)}

Das 20 amostras positivas na IFD, 18 foram confirmadas como positivas pelo IVC. O período mínimo de incubação para ambas as espécies foi de 07 dias e o máximo de 13, entretanto, duas amostras de equinos não resultaram positivas no IVC. Camundongos inoculados com suspensões de TE de equinos tiveram um período mínimo de incubação mais longo, de 12 dias.

\section{Imuno-histoquímica (IHQ)}

Apenas uma amostra foi negativa para a raiva pelo uso da IHQ. Esta amostra foi positiva na IFD, apresentando baixa intensidade de fluorescência.

Observou-se que as células mais frequentemente infectadas foram neurônios, com raras células gliais. Células de Purkinje foram frequentemente infectadas, sendo, portanto, o cerebelo, uma região muito indicada para o diagnóstico da raiva nestas espécies.

As alterações histopatológicas caracterizaram-se, principalmente, por infiltração linfocitária, evidenciando uma meningoencefalite, neuroniofagia, gliose, inclusões intracitoplasmáticas/corpúsculos de Negri e vacuolização neuronal.

\section{Interpretação dos resultados}

Na Figura 1 são apresentadas ilustrações de lâminas positivas e os respectivos controles negativos nas técnicas analisadas e pela coloração por HE.

A determinação da positividade nos diferentes fragmentos de SNC, está demonstrada nos Quadros 1 e 2. Os resultados obtidos mostram que apenas uma amostra de equino, positiva na IFD, foi negativa para a IHQ.

A diferença da frequência das classes de concentração antigênica dos quatro fragmentos, nas duas espécies estudadas está demonstrada na Fig.2. Em relação às técnicas, observou-se que as maiores frequências de concentração antigênica das amostras analisadas pela IFD pertenciam a classe 3 , em fragmentos de CB e TE e pela $\mathrm{IHQ}$, à classe 2, em fragmentos de $\mathrm{H}$. Em relação às espécies, amostras de bovinos apresentaram maior concen- 
tração antigênica em ambas as técnicas. Os resultados da IFD e da IHQ dos fragmentos de CB e TE de equinos foram mais concordantes, quando correlacionados com os de bovinos.

A Figura 3 representa a infecção pelo vírus da raiva em diferentes fragmentos do SNC, através das técnicas de IFD e IHQ.

Os resultados da avaliação da sensibilidade da técnica de IHQ nos diferentes fragmentos de SNC analisados estão expressos no Quadro 3. Observou-se que a técnica
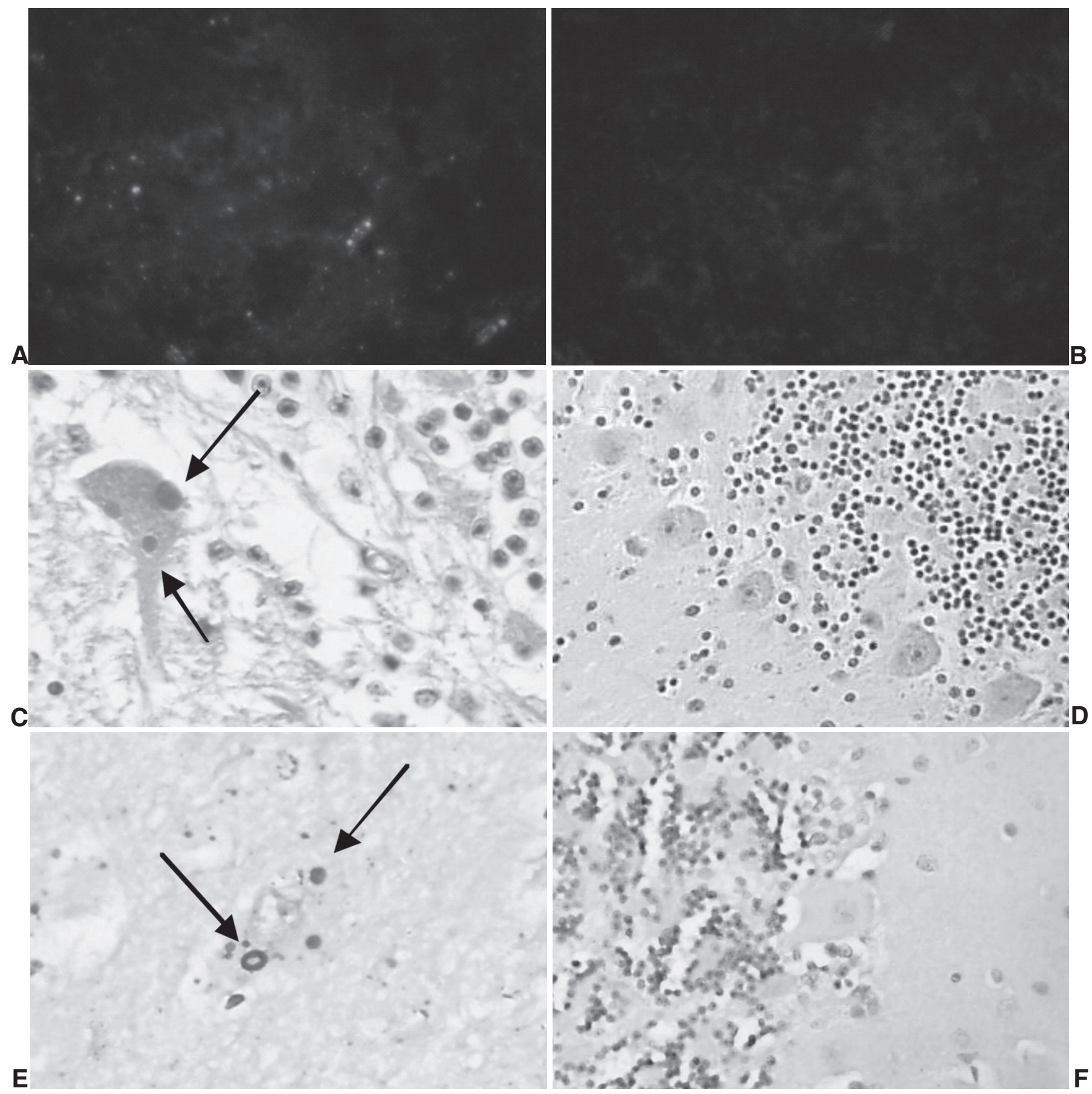

Fig.1. (A) Cerebelo de eqüino infectado pelo vírus da raiva. Os focos fluorescentes indicam inclusões de Negri. Imunofluorescência direta, obj.40x. (B) Cerebelo de eqüino negativo para raiva. Imunofluorescência direta, obj.40x. (C) Cerebelo de bovino infectado pelo vírus da raiva. As setas indicam inclusões intracitoplasmáticas em um neurônio. HematoxilinaEosina, obj.40x. (D) Córtex cerebral de bovino sem infecção por vírus da raiva. Hematoxilina-Eosina, obj.40x. (E) Infecção do Cerebelo de eqüino por vírus da raiva. As setas indicam inclusões intracitoplasmáticas em um neurônio. Imuno-histoquímica, obj.40x. (F) Corte de cerebelo de eqüino negativo para raiva. Imuno-histoquímica, obj.40x. 
Quadro 1. Comparação da positividade das técnicas de IFD ${ }^{a}$ e IHQ ${ }^{b}$ em fragmentos do $\mathrm{SNC}^{c}$ de bovinos infectados naturalmente pelo vírus da raiva. A determinação das classes de intensidade das reações está descrita como sendo: (-) ausência de inclusões antigênicas, (+) 1 a 3 inclusões, $(++)$ poucas inclusões e campos negativos, $(+++)$ distribuição homogenia de inclusões e campos negativos, (++++) distribuição homogenia de inclusões sem campos negativos

\begin{tabular}{|c|c|c|c|c|c|c|c|c|}
\hline \multirow[t]{3}{*}{ Amostra } & \multicolumn{8}{|c|}{ Técnica } \\
\hline & \multicolumn{4}{|c|}{ IFD } & \multicolumn{4}{|c|}{$\mathrm{IHQ}$} \\
\hline & $\mathrm{H}^{\mathrm{d}}$ & $c x^{e}$ & $\mathrm{CB}^{f}$ & TE $^{g}$ & $\mathrm{H}^{\mathrm{d}}$ & $c x^{e}$ & $\mathrm{CB}^{f}$ & $\mathrm{TE}^{\mathrm{g}}$ \\
\hline 131 & + & + & + & +++ & + & + & ++ & + \\
\hline 191 & ++ & ++ & ++ & ++ & + & ++ & ++ & ++ \\
\hline 588 & + & ++ & +++ & +++ & - & ++ & ++ & ++ \\
\hline 1920 & +++ & +++ & +++ & +++ & ++ & ++ & +++ & +++ \\
\hline 2166 & ++ & ++++ & ++++ & ++++ & + & ++ & +++ & +++ \\
\hline 2630 & ++ & ++ & +++ & +++ & + & + & ++ & ++ \\
\hline 3577 & + & ++ & +++ & +++ & - & + & ++ & ++ \\
\hline 4001 & ++ & ++ & +++ & +++ & + & + & +++ & +++ \\
\hline 6049 & ++ & ++ & +++ & +++ & + & + & ++ & ++ \\
\hline 10647 & + & + & + & ++ & + & + & + & + \\
\hline
\end{tabular}

${ }^{a}$ Imunofluorescência direta, ${ }^{b}$ imuno-histoquímica, ${ }^{c}$ sistema nervoso central, ${ }^{d}$ hipocampo, ${ }^{e}$ córtex cerebral, ${ }^{f}$ cerebelo, 9 tronco encefálico.
Quadro 2. Comparação da positividade das técnicas de IFD ${ }^{a}$ e IHQ ${ }^{b}$ em fragmentos do $S_{N C}^{c}$ de eqüinos infectados naturalmente pelo vírus da raiva. A determinação das classes de intensidade das reações está descrita como sendo: (-) ausência de inclusões antigênicas, (+) 1 a 3 inclusões, $(++)$ poucas inclusões e campos negativos, $(+++)$ distribuição homogenia de inclusões e campos negativos, (++++) distribuição homogenia de inclusões sem campos negativos

\begin{tabular}{|c|c|c|c|c|c|c|c|c|}
\hline \multirow[t]{3}{*}{ Amostra } & \multicolumn{8}{|c|}{ Técnica } \\
\hline & \multicolumn{4}{|c|}{ IFD } & \multicolumn{4}{|c|}{$\mathrm{IHQ}$} \\
\hline & $\mathrm{H}^{\mathrm{d}}$ & $c x^{e}$ & $\mathrm{CB}^{f}$ & TE $^{g}$ & $\mathrm{H}^{\mathrm{d}}$ & $c X^{e}$ & $\mathrm{CB}^{f}$ & $\mathrm{TE}^{\mathrm{g}}$ \\
\hline 1594 & ++ & ++ & ++ & ++ & - & + & ++ & + \\
\hline 1696 & - & - & + & ++ & - & + & ++ & ++ \\
\hline 2162 & ++ & ++ & +++ & +++ & + & ++ & +++ & ++ \\
\hline 2552 & +++ & +++ & +++ & ++++ & ++ & +++ & +++ & +++ \\
\hline 3357 & + & + & + & + & - & - & + & - \\
\hline 3829 & + & + & ++ & +++ & + & + & ++ & ++ \\
\hline 5037 & ++ & ++ & ++ & ++ & ++ & ++ & ++ & ++ \\
\hline 5790 & + & + & + & + & - & - & - & - \\
\hline 7955 & + & + & + & + & + & + & + & + \\
\hline 9146 & + & + & ++ & ++ & - & - & ++ & + \\
\hline
\end{tabular}

a Imunofluorescência direta, ${ }^{b}$ imuno-histoquímica, ${ }^{c}$ sistema nervoso central, ${ }^{d}$ hipocampo, ${ }^{e}$ córtex cerebral, ${ }^{f}$ cerebelo, 9 tronco encefálico.
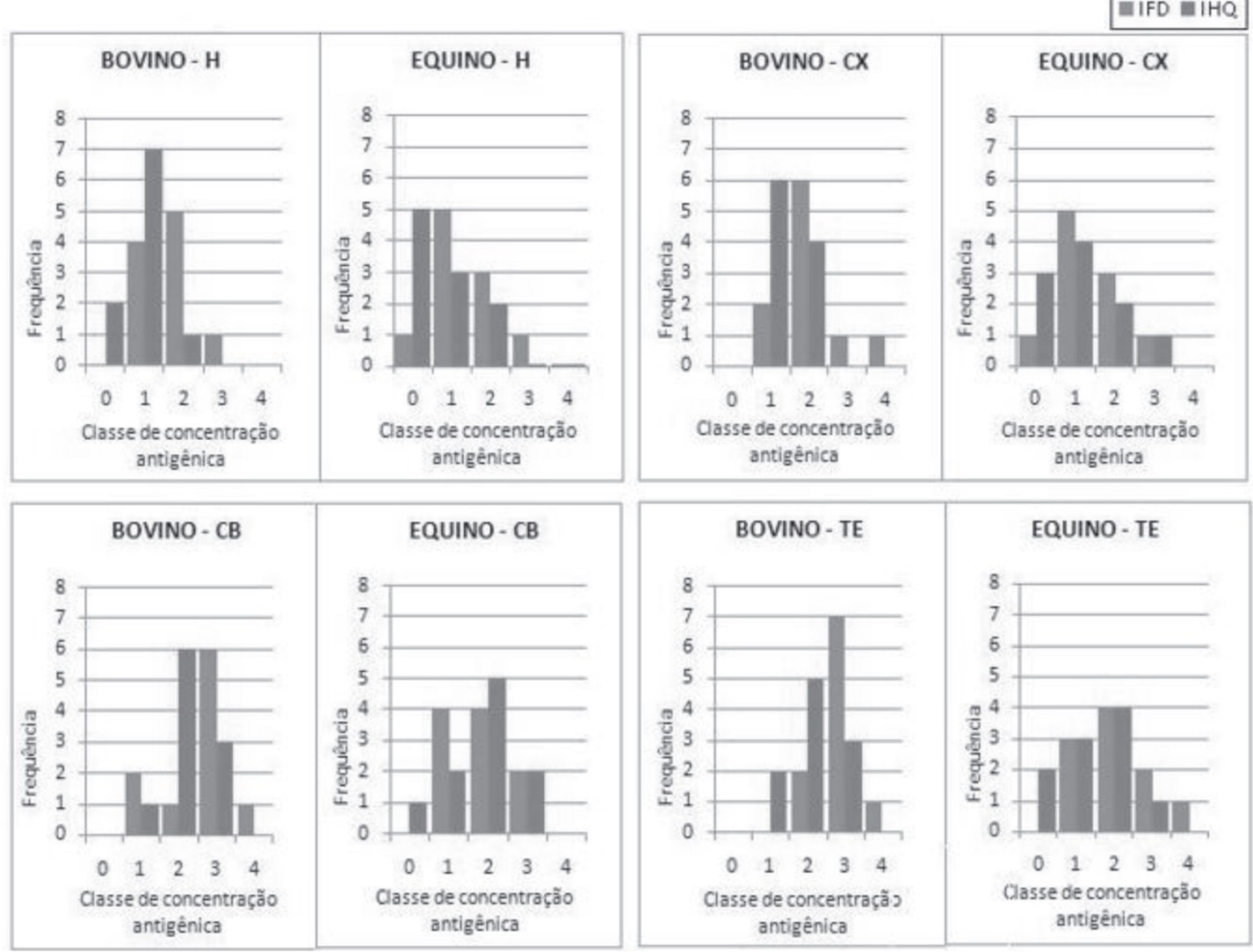

Fig.2. Frequência das classes de concentração antigênica dos fragmentos de hipocampo $(H)$, córtex cerebral (CX), cerebelo (CB) e tronco encefálico (TE) de bovinos e eqüinos infectados naturalmente pelo vírus da raiva, através das técnicas de imunofluorescência direta (IFD) e imuno-histoquímica (IHQ). 

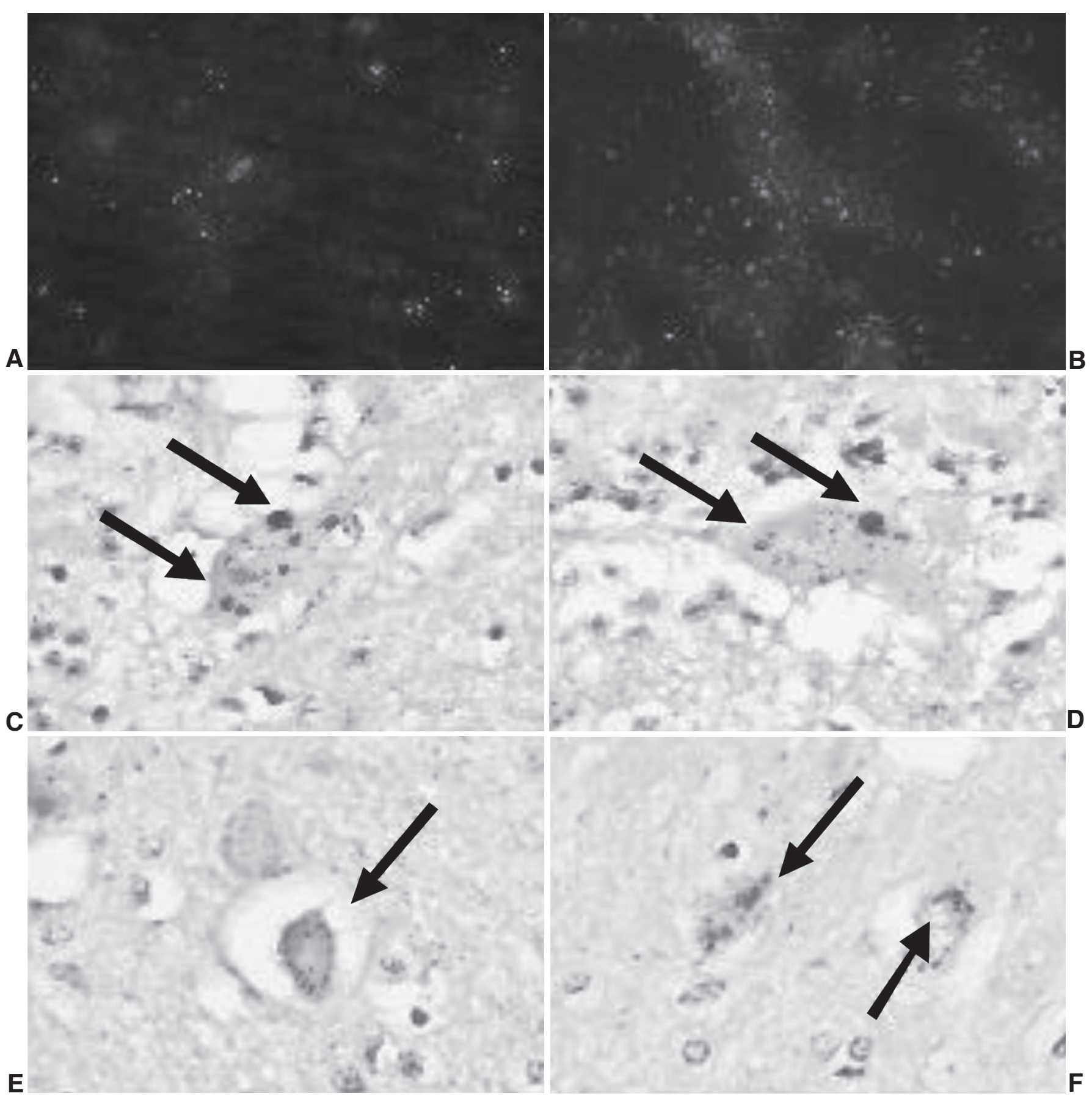

Fig.3. (A) Neurônios do cerebelo de eqüino infectados pelo vírus da raiva. Imunofluorescência direta, obj.40x. (B) Neurônios do tronco encefálico de bovino infectado pelo vírus da raiva. Imunofluorescência direta, obj.40x. (C,D) Infecção do cerebelo de bovino pelo vírus da raiva. As setas indicam um neurônio com várias inclusões intracitoplasmáticas. Imunohistoquímica, obj.40x. (E,F) Infecção do tronco encefálico de eqüino pelo vírus da raiva. As setas indicam várias inclusões intracitoplasmáticas. Imuno-histoquímica, obj.40x.

de IHQ apresenta maior sensibilidade, comparada à IFD, para detecção de antígeno da raiva em tecido parafinado de amostras de bovinos.

\section{DISCUSSÃO}

A técnica de IHQ, assim como a IFD, utiliza anticorpos específicos para detectar inclusões/corpúsculos e proteínas virais. A utilização de enzimas marcadoras aumenta a sensibilidade da técnica (Ramos-Vara 1999).

Métodos imunohistoquímicos têm sido utilizados na detecção do antígeno da raiva em tecidos fixados em formol (Hamir et al. 1992, López et al. 1998-2001, Woldehiwet 2005). A técnica de IHQ também tem sido 


\begin{abstract}
Quadro 3. Sensibilidade da técnica de $\mathrm{IHQ}^{\mathrm{a}}$ em comparação com a IFD nos diferentes fragmentos de $\mathrm{SNC}^{\mathrm{C}}$ de herbívoros suspeitos de raiva
\end{abstract}

\begin{tabular}{ccc}
\hline \multirow{2}{*}{ Fragmento de SNC } & \multicolumn{2}{c}{ Sensibilidade IHQ } \\
\cline { 2 - 3 } & Bovinos & Eqüinos \\
\hline $\mathrm{H}^{\mathrm{d}}$ & $80 \%$ & $55 \%$ \\
$\mathrm{CX}^{\mathrm{e}}$ & $100 \%$ & $77 \%$ \\
$\mathrm{CB}^{\mathrm{f}}$ & $100 \%$ & $90 \%$ \\
TE $^{\mathrm{g}}$ & $100 \%$ & $80 \%$
\end{tabular}

a Imuno-histoquímica, ${ }^{b}$ imunofluorescência direta, ${ }^{\mathrm{c}}$ sistema nervoso central, ${ }^{\mathrm{d}}$ hipocampo, ${ }^{\mathrm{e}}$ córtex cerebral, ${ }^{\mathrm{f}}$ cerebelo,

$\mathrm{g}$ tronco encefálico.

aplicada em biópsias de folículo piloso, para o diagnóstico ante-mortem da raiva (Bagó et al. 2005).

Estudos indicam que a detecção de antígenos da raiva através da técnica de IHQ é mais sensível do que a detecção de corpúsculos de Negri visualizados pela coloração de $\mathrm{HE}$ e tão sensível quanto à IFD (Woldehiwet 2005). Outros autores ainda indicam uma maior sensibilidade da IHQ em relação à IFD (Bourgon \& Charlton 1987). Tao et al. (2008) demonstraram que a sensibilidade e especificidade da IHQ são equivalentes às técnicas de IFD e RT-PCR. A IHQ apresenta, ainda, a grande vantagem de permitir a realização de estudos retrospectivos, quando aplicada em amostras previamente emblocadas, colaborando com estudos de vigilância epidemiológica.

Vários estudos discutem quais seriam os fragmentos mais indicados para a detecção de antígenos virais, embora os fragmentos que contêm antígenos com maior frequência podem variar, de acordo com a patogenicidade e tropismo da amostra viral em questão e de acordo com a espécie animal.

Peixoto et al. (2000) demonstraram que, no diagnóstico da raiva em amostras de SNC de equinos, a sensibilidade da IFD em relação ao IVC é de $76,6 \%$ e que o percentual de falsos negativos na IFD poderia chegar a $20 \%$. Carrieri et al. (2006), ao analisarem amostras de origem equina, evidenciaram que além da sensibilidade entre essas duas técnicas depender do fragmento utilizado, ocorriam baixas concentrações virais no córtex cerebral, hipocampo e cerebelo, sendo a medula e o tronco encefálico as seções mais recomendados para o diagnóstico laboratorial.

O presente estudo demonstrou que, na amostragem estudada, a técnica de IHQ apresentou $100 \%$ de sensibilidade, comparada à IFD, para detecção de antígeno da raiva em tecido parafinado de amostras de bovinos naturalmente infectados, especialmente em fragmentos de córtex cerebral, cerebelo e tronco encefálico. Esta sensibilidade é ligeiramente inferior quando se trata de fragmentos de cerebelo e tronco encefálico de equinos e, mais ainda, de córtex cerebral e hipocampo destes animais. Tanto na IFD quanto na IHQ, os fragmentos com maior distribuição viral foram o cerebelo e o tronco encefálico.

Os resultados apresentados neste estudo demonstraram eficácia da IHQ no diagnóstico da raiva, podendo ser esta mais uma ferramenta a ser utilizada na vigilância epidemiológica da doença, já que podem ser diagnosticadas amostras eventualmente fixadas em formol, o que inviabiliza a execução das técnicas clássicas preconizadas pela OMS. Para tanto, procedimentos bem empregados são necessários para que não se comprometa a execução da técnica de forma irreversível, como uma boa fixação em soluções tamponadas e em períodos pré-estabelecidos. Além disso, recomenda-se cautela ao se empregar a IHQ para diagnóstico da raiva bovina e equina, especialmente quando o fragmento encaminhado ao laboratório for apenas o hipocampo, já que, como visto anteriormente por outros autores, este fragmento pode apresentar baixas concentrações de antígenos virais.

\section{CONCLUSÕES}

A imuno-histoquímica pode ser uma técnica alternativa para o diagnóstico da raiva em situações nas quais a conservação em condições de refrigeração não é possível, tendo em vista sua alta sensibilidade em relação à imunofluorescência direta, que é considerada padrão ouro para o diagnóstico da doença.

Como as maiores dificuldades do diagnóstico da raiva são descritas na espécie equina, em função do fragmento a ser utilizado, e a alta sensibilidade da IHQ em relação à IFD demonstrada neste trabalho, pode-se considerar que a IHQ pode ser aplicada em amostras de diferentes espécies animais.

\section{REFERÊNCIAS}

Acha P.N. \& Szyfres B. 1996. Zoonosis y Enfermedades Transmisibles Comunes al Hombre y los Animales. $2^{\underline{a}}$ ed. Organización Pan-Americana de la Salud, Washington, p.502-526.

Bagó Z., Revilla-Fernández S. \& Allerberger F. 2005. Value of immunohistochemistry for rapid ante mortem rabies diagnosis. Int. J. Infect. Dis. 9:351-352.

Brasil 2009. Raiva Humana, Brasil, 1986-2009. Coordenação de Vigilância das Doenças Transmissíveis por Vetores e Antropozoonoses, Coordenação Geral de Doenças Transmissíveis, Secretaria de Vigilância em Saúde, Ministério da Saúde. Acesso em 11 de maio de 2009. http://portal.saude.gov.br

Brass D.A. 1994. Rabies and rabies-related viruses of Africa, p.263273. In: Brass D.A. (Ed.), Rabies in Bats: Natural history and public health implications. Livia Press, Connecticut.

Bourgan A.R. \& Charlton K.M. 1987. The demonstration of rabies antigen in paraffin-embedded tissues using the peroxidase-antiperoxidase method: A comparative study. Can. Vet. J. 51:117-120.

Carini A. 1911. Sur une grande épizootic de rage. Ann. Inst. Pasteur 25:843-846.

Carnieli Jr P., Castilho J.G., Fahl W. de O., Véras N.M., Carrieri M.L. \& Kotait I. 2009. Molecular characterization of rabies virus isolates from dogs and crab-eating foxes in northeastern Brazil. Virus Res. 141(1):8189.

Carrieri M.L., Peixoto Z.M.P., Paciencia M.L.B., Kotait I. \& Germano P.M.L. 2006. Laboratory diagnosis of equine rabies and its implications for human postexposure prophylaxis. J. Virol. Meth. 2:1-9.

Dean D.J., Abelseth M.K. \& Atanasiu P. 1996. Fluorescent antibody test, p.88-95. In: Meslin F.-X., Kaplan M.M. \& Koprowski H. (Eds), Laboratory Techniques in Rabies. $4^{\text {th }}$ ed. World Health Organization, Geneva. 
Diaz A.M., Papo S., Rodriguez A. \& Smith J.S. 1994. Antigenic analysis of rabies-virus isolates from Latin America and the Caribbean. Zentralbl. Veterinärmed. B 41:153-160.

Fauquet C.M., Mayo M.A., Maniloff J., Desselberger U. \& Ball L.A. 2005. Virus taxonomy, p.630-634. In: Eighth Report of the International Committee on Taxonomy of Viruses, Academic Press, San Diego, CA.

Feital A.S.S. \& Confalonieri U.E.C. 1998. Estudo epidemiológico da raiva bovina no estado do Rio de Janeiro, Brasil (1980-1992). Revta Bras. Ciênc. Vet., Rio de J., 5(1):21-27.

Fernandes E.R. 2009. O processo inflamatório, a resposta imune "in situ" e a morte neuronal em sistema nervoso central de pacientes com raiva transmitida por morcegos. Tese apresentada na Faculdade de Medicina da Universidade de São Paulo. 248p.

Forattini O.P. 1980. Epidemiologia Geral. Artes Médicas, São Paulo, p.117-131.

Hamir A.N., Moser G. \& Rupprecht C.E. 1992. Morphologic and immunoperoxidase study of neurologic lesions in naturally acquired rabies of raccoons. J. Vet. Diag. Invest. 4:369-373.

Haupt H. \& Rehaag H. 1925. Raiva epizoótica nos rebanhos de Santa Catarina transmitida por morcegos. Bolm Soc. Bras. Med. Vet. 2:1747.

Koprowsky H. 1996. The mouse inoculation test, p.80-87. In: Meslin F.X., Kaplan M.M. \& Koprowski H. (Eds), Laboratory Techniques in Rabies. $4^{\text {th }}$ ed. World Health Organization, Geneva.

Kotait I., Gonçalves C.A., Peres N.F., Souza M.C.A.M. \& Targueta M.C. 1998. Controle da raiva dos herbívoros. Manual Técnico do Instituto Pasteur, São Paulo, 1:5-11.

López J.W. 1998/2001. Immunohistochemical recognition of a wide spectrum of Lyssavirus in formalin-fixed tissues by one monoclonal antibody. Boln Centro Panam. Fiebre Aftosa, Rio de J., 64/67:18-25.
Mori A.E. \& Lemos R.A.A. 1998. Raiva, p.47-58. In: Lemos R.A.A. (Ed.), Principais Enfermidades de Bovinos de Corte do Mato Grosso do Sul: Reconhecimento e diagnóstico. Universidade Federal do Mato Grosso do Sul, Campo Grande.

Peixoto Z.M.P., Cunha E.M.S. \& Sacramento D. 2000. Rabies laboratory diagnosis: Peculiar features of samples from equine origin. Braz. J. Microbiol. 31:72-75.

Ramos-Vara J.A. 1999. Diagnosing infectious porcine diseases using immunohistochemistry. Swine Health Prod. 7:85-91.

Rupprecht C.E., Hanlon C.A. \& Hemachudha T. 2002. Rabies reexamined. Lancet Infect. Dis. 2(6):327-343.

Smith J.S. 1996. New aspects of rabies with emphasis on epidemiology, diagnosis and prevention of the disease in the United States. Clin. Microbiol. Rev. 9(2):166-176.

Tao X.Y., Niezgoda M., Du J.L. \& Li H. 2008. The primary application of direct rapid immunohistochemical test to rabies diagnosis in China. Zhonghua Shi Yan He Lin Chuang Bing Du Xue Za Zhi 22(3):168-170.

Tierkel E.S. 1976. Investigación microscópica rápida de corpúsculos de Negri y preparación de muestras para las pruebas biológicas, p.4257. In: Kaplan M.M. \& Koprowski H. (Eds), La Rabia Tecnicas de Laboratório. Organizacion Mundial de la Salud, Genebra.

Tordo N., Bourhy H. \& Sacramento D. 1995. PCR technology for Lyssavirus diagnosis, p.125-145. In: Clewley J. (Ed.), The Polymerase Chain Reaction (PCR) for Human Viral Diagnosis. CRC Press, London.

Webster W.A. \& Casey G.A. 1996. Virus isolation in neuroblastoma cell culture, p.96-104. In: Meslin F.X., Kaplan M.M. \& Koprowski H. (Eds), Laboratory Techniques in Rabies. $4^{\text {th }}$ ed. World Health Organization, Geneva.

Woldehiwet Z. 2005. Clinical laboratory advances in the detection of rabies virus. Clin. Chim. Acta 351:49-63. 